\title{
Oxidative Stress Promotes Asexual Reproduction and Apogamy in the Red Seaweed Pyropia yezoensis
}

\author{
Megumu Takahashi' and Koji Mikami2* \\ ${ }^{1}$ Department of Aquatic Bioscience, Faculty of Bio-Industry, Tokyo University of Agriculture, Abashiri, Japan, ${ }^{2}$ Laboratory of \\ Aquaculture, Genetics and Genomics, Division of Marine Life Science, Faculty of Fisheries Sciences, Hokkaido University, \\ Hakodate, Japan
}

OPEN ACCESS

Edited by:

Stefan A. Rensing,

University of Marburg, Germany

Reviewed by:

Nayelli Marsch-Martinez,

Centro de Investigacion y de Estudios Avanzados del Instituto Politecnico

Nacional, Mexico Jonas Collén,

Université Pierre et Marie Curie,

France

*Correspondence:

Koji Mikam

komikami@fish.hokudai.ac.jp

Specialty section:

This article was submitted to Plant Evolution and Development,

a section of the journal

Frontiers in Plant Science

Received: 21 October 2016 Accepted: 11 January 2017 Published: 27 January 2017

Citation:

Takahashi M and Mikami K (2017) Oxidative Stress Promotes Asexual Reproduction and Apogamy in the Red Seaweed Pyropia yezoensis. Front. Plant Sci. 8:62. doi: 10.3389/fpls.2017.00062
The marine red seaweed Pyropia yezoensis has a haploid-diploid life cycle wherein two heteromorphic generations, a haploid gametophyte and a diploid sporophyte, are reciprocally generated from conchospores and carpospores, respectively. When we treated gametophytic blades of $P$. yezoensis with $\mathrm{H}_{2} \mathrm{O}_{2}$, discharge of asexual monospores was accelerated, resulting in increased numbers of gametophytic clones. Production of sporophytes without fertilization of male and female gametes was also observed. These findings indicate that oxidative stress can induce vegetative cells to develop into monospores that produce gametophytes asexually and can sometimes prompt carpospores to develop into sporophytes. The discovery of oxidative stresstriggered asexual reproduction and -apogamy will stimulate progress in studies of life-cycle regulation in $P$. yezoensis.

\section{Keywords: apogamy, oxidative stress, life cycle, generation switch, Pyropia yezoensis}

\section{INTRODUCTION}

Plants are multicellular organisms that exhibit alternation of ontogenies, such as haploid gametophyte and diploid sporophyte generations, during their life cycles (Coelho et al., 2011a; Bowman et al., 2016; Horst and Reski, 2016), such that a single nuclear genome operates two different developmental programs (Friedman, 2013). Developmental programs for haploid and diploid generations are initiated by meiosis to produce haploid spores and fertilization of male and female gametes to produce diploid spores, respectively. However, homeotic mutations that induce apomixis, i.e., a switch between generation without fertilization or meiosis, have been reported in terrestrial plants (Bell, 1992; Schmidt et al., 2015). Apomixis encompasses two developmental processes, namely apospory (the occurrence of a gametophyte from a sporophyte without meiosis) and apogamy (the occurrence of a sporophyte from a gametophyte without fertilization). Thus, apomixis is a highly useful tool with which to elucidate the regulatory mechanisms of reprograming required for generation switching.

The life-cycle of the red seaweed Pyropia yezoensis, previously referred as Porphyra yezoensis and recently renamed according to the novel classification of Bangiales (Sutherland et al., 2011), has been extensively studied and comprises the reciprocal appearance of free-living haploid gametophytes and diploid sporophytes as leafy blades and filamentous conchocelis as shown in Figure 1 (Sahoo et al., 2002; Shimizu et al., 2008; Blouin et al., 2011; Mikami et al., 2012; Herron et al., 2013). Like other organisms, P. yezoensis requires fertilization and meiosis for the transitions from gametophyte to sporophyte and from sporophyte to gametophyte, respectively (Figure 1). Despite the accumulation of knowledge about its life cycle, mechanisms regulating the generation-to-generation transitions in P. yezoensis have not been well studied to date. The present 


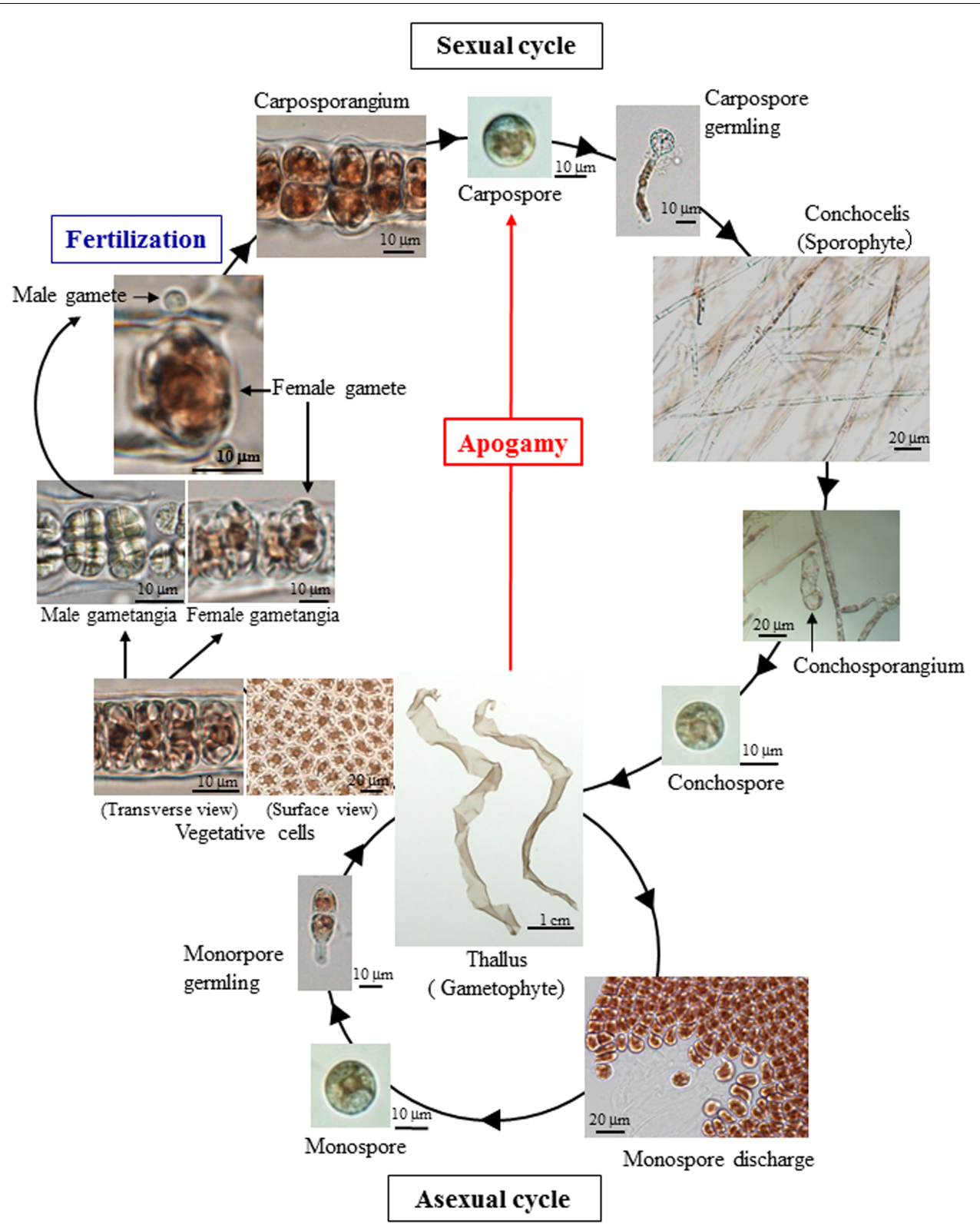

FIGURE 1 | Life cycle of the marine red seaweed Pyropia yezoensis. Monospores and carpospores are released from an asexual gametophyte and fertilization-dependent carposporangium, respectively. However, apogamy produces carpospores directly from gametophyte without fertilization.

work sought to provide information about the effect of reactive oxygen species on $P$. yezoensis reproduction, which is not known. We here found that oxidative stress can promote the generation switch through apogamy in $P$. yezoensis.

\section{MATERIALS AND METHODS}

Gametophytic blades of $P$. yezoensis strain U-51 were cultured in PES medium, which was made using filtered natural seawater with PES [Provasoli's enriched seawater; Provasoli (1968)] solution, under $60 \mu \mathrm{mol} / \mathrm{m}^{2} / \mathrm{s}$ irradiance with a photocycle of $10 \mathrm{~h}$ light and $14 \mathrm{~h}$ dark at $15^{\circ} \mathrm{C}$. The PES medium was continuously bubbled with filter-sterilized air and renewed weekly. Gametophytes of ca. $10 \mathrm{~mm}$ length (whole blades) were used for experiments. $\mathrm{H}_{2} \mathrm{O}_{2}$ was dissolved in distilled water (DW) to create a $0.1 \mathrm{M}$ stock solution. We employed total six blades per experiment by dividing into three sets (two individuals per set) to perform standing-culture using three upper wells of a 6-well culture dish (Iwaki Sci Tech Div., Asahi Techno Glass, Japan) containing $5 \mathrm{~mL}$ PES medium for 2 weeks at $15^{\circ} \mathrm{C}$ with addition of the $\mathrm{H}_{2} \mathrm{O}_{2}$ solution at working concentrations indicated in the text or DW corresponding to the maximum volume of the $\mathrm{H}_{2} \mathrm{O}_{2}$ stock solution. The 
concentration of the solutions did not exceed $1 \%$ after addition to the medium. Culture medium was renewed weekly by replacing gametophytes to a new well containing new medium. After $\mathrm{H}_{2} \mathrm{O}_{2}$ treatment, the numbers of monospore germlings, carpospore germlings and non-germinating spores in each well were counted under an inverted light microscope (CKX41, Olympus, Tokyo, Japan) equipped with a camera (DP26, Olympus).

\section{RESULTS AND DISCUSSION}

When each set of two $P$. yezoensis gametophytes was treated with $0,0.5$, or $1.0 \mathrm{mM} \mathrm{H} \mathrm{H}_{2} \mathrm{O}_{2}$, production and release of asexual monospores was accelerated (Figure 2A), although effects of $\mathrm{H}_{2} \mathrm{O}_{2}$ varied among experiments (Table 1). Thus, oxidative stress is one factor promoting monospore discharge for asexual propagation. In plants, it is well known that oxidative stress enhances photosynthesis (Foyer and Shigeoka, 2011) and stimulates $\mathrm{Ca}^{2+}$ influx (Mori and Schroeder,

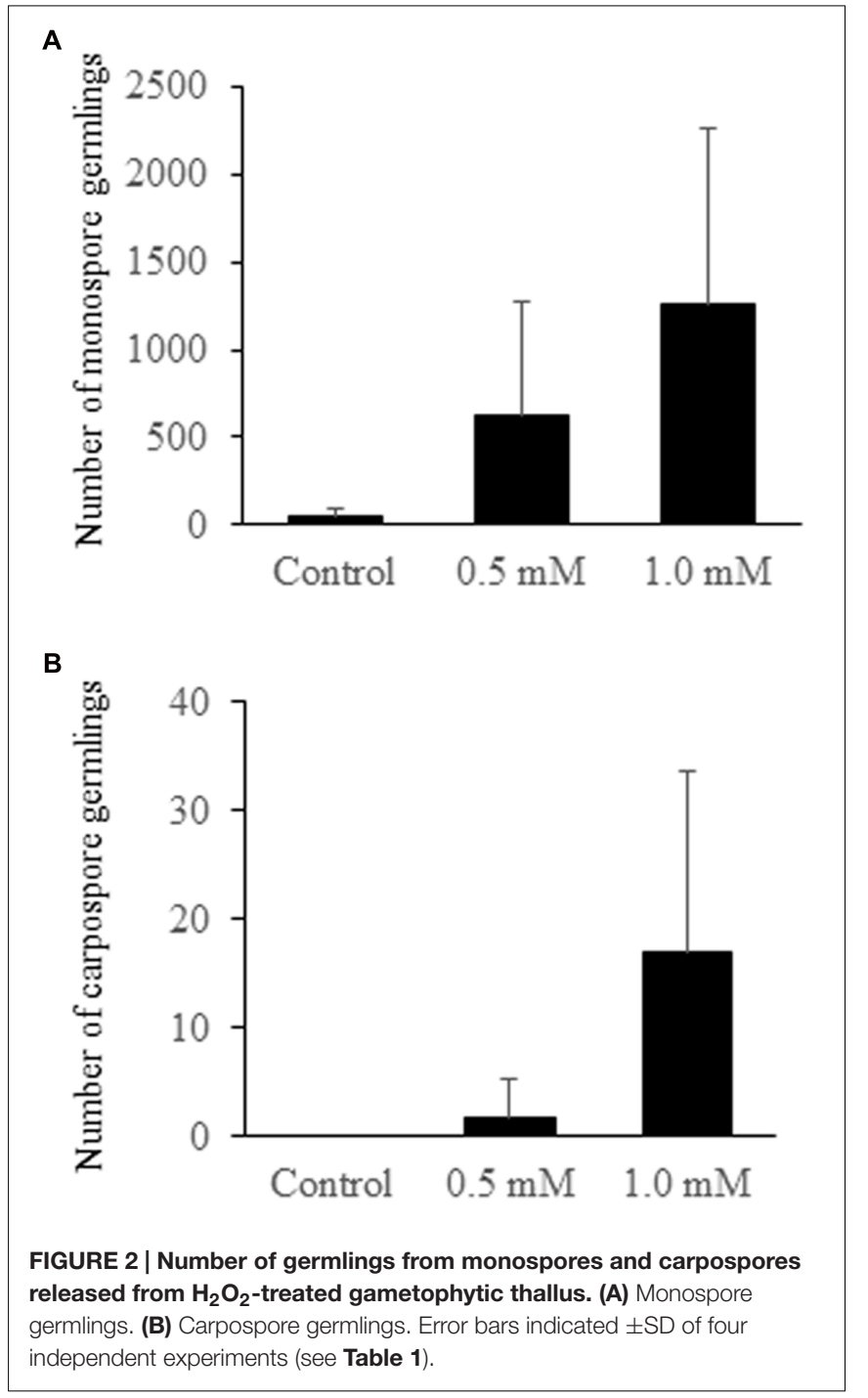

TABLE 1 | Number of germlings from monospores and carpospores released from $\mathrm{H}_{2} \mathrm{O}_{2}$-treated gametophytic thallus in four independent experiments.

\begin{tabular}{|c|c|c|c|}
\hline Conditions & $\begin{array}{l}\text { Monospore } \\
\text { germlings }\end{array}$ & $\begin{array}{l}\text { Carpospore } \\
\text { germlings }\end{array}$ & $\begin{array}{l}\text { Non-germinating } \\
\text { spore }\end{array}$ \\
\hline \multicolumn{4}{|l|}{ Experiment 1} \\
\hline Control & 91 & 0 & 5 \\
\hline $0.5 \mathrm{mM} \mathrm{H}_{2} \mathrm{O}_{2}$ & 480 & 0 & 5 \\
\hline $1.0 \mathrm{mM} \mathrm{H}_{2} \mathrm{O}_{2}$ & 1964 & 30 & 25 \\
\hline \multicolumn{4}{|l|}{ Experiment 2} \\
\hline Control & 1 & 0 & 0 \\
\hline $0.5 \mathrm{mM} \mathrm{H}_{2} \mathrm{O}_{2}$ & 442 & 0 & 5 \\
\hline $1.0 \mathrm{mM} \mathrm{H}_{2} \mathrm{O}_{2}$ & 687 & 2 & 25 \\
\hline \multicolumn{4}{|l|}{ Experiment 3} \\
\hline Control & 2 & 0 & 0 \\
\hline $0.5 \mathrm{mM} \mathrm{H}_{2} \mathrm{O}_{2}$ & 37 & 0 & 0 \\
\hline $1.0 \mathrm{mM} \mathrm{H}_{2} \mathrm{O}_{2}$ & 154 & 3 & 77 \\
\hline \multicolumn{4}{|l|}{ Experiment 4} \\
\hline Control & 92 & 0 & 6 \\
\hline $0.5 \mathrm{mM} \mathrm{H}_{2} \mathrm{O}_{2}$ & 1555 & 7 & 17 \\
\hline $1.0 \mathrm{mM} \mathrm{H}_{2} \mathrm{O}_{2}$ & 2240 & 33 & 20 \\
\hline
\end{tabular}

Two gametophytes were used for each assay (six individuals per experiment).

2004; Rentel and Knight, 2004). We previously reported that a $\mathrm{Ca}^{2+}$ influx that requires photosynthetic activity is responsible for monospore discharge in P. yezoensis (Takahashi et al., 2010). Thus, it is possible that $\mathrm{H}_{2} \mathrm{O}_{2}$ treatment of gametophytic thallus activates photosynthesis-dependent $\mathrm{Ca}^{2+}$ influx to promote release of monospores. This possibility would suggest that $P$. yezoensis may harbor $\mathrm{H}_{2} \mathrm{O}_{2}$-dependent $\mathrm{Ca}^{2+}$ transporters.

We also observed an induction of apogamy resulting in the production of sporophytes from released spores without development and fertilization of male and female gametes (Figure 3A), although at low-frequency (Figure 2B; Table 1). Since the apogamous sporophytes generated conchosporangia from which conchospores were produced and developed into normal gametophytes (Figures 3B-E), carpospores generated under oxidative stress conditions were indistinguishable from those produced in conchosporangia via the normal life cycle (Figure 1), suggesting diploidy of apogamous sporophytes, although it should be confirmed. Thus, oxidative stress has the potential to reprogram the developmental fate of a gametophytic vegetative cell to produce carpospores from which sporophytes develop. This finding represents the first evidence of abiotic stress-induced apogamy in seaweeds.

Previously, it was reported that sporophyte development from gametophytic cells could be artificially induced in the red seaweed Pyropia pseudolinearis when free cells were prepared by treatment of thallus with allantoin followed by homogenization (Saito et al., 2008). Allantoin is a purine metabolite (Bai et al., 2006) that activates jasmonic acid (JA) signaling in an abscisic acid (ABA)-dependent manner in Arabidopsis thaliana (Watanabe et al., 2014; Takagi et al., 2016). Although P. yezoensis lacks endogenous JA, it contains ABA (Mikami et al., 2016). It is possible that allantoin stimulates ABA biosynthesis in P. yezoensis 

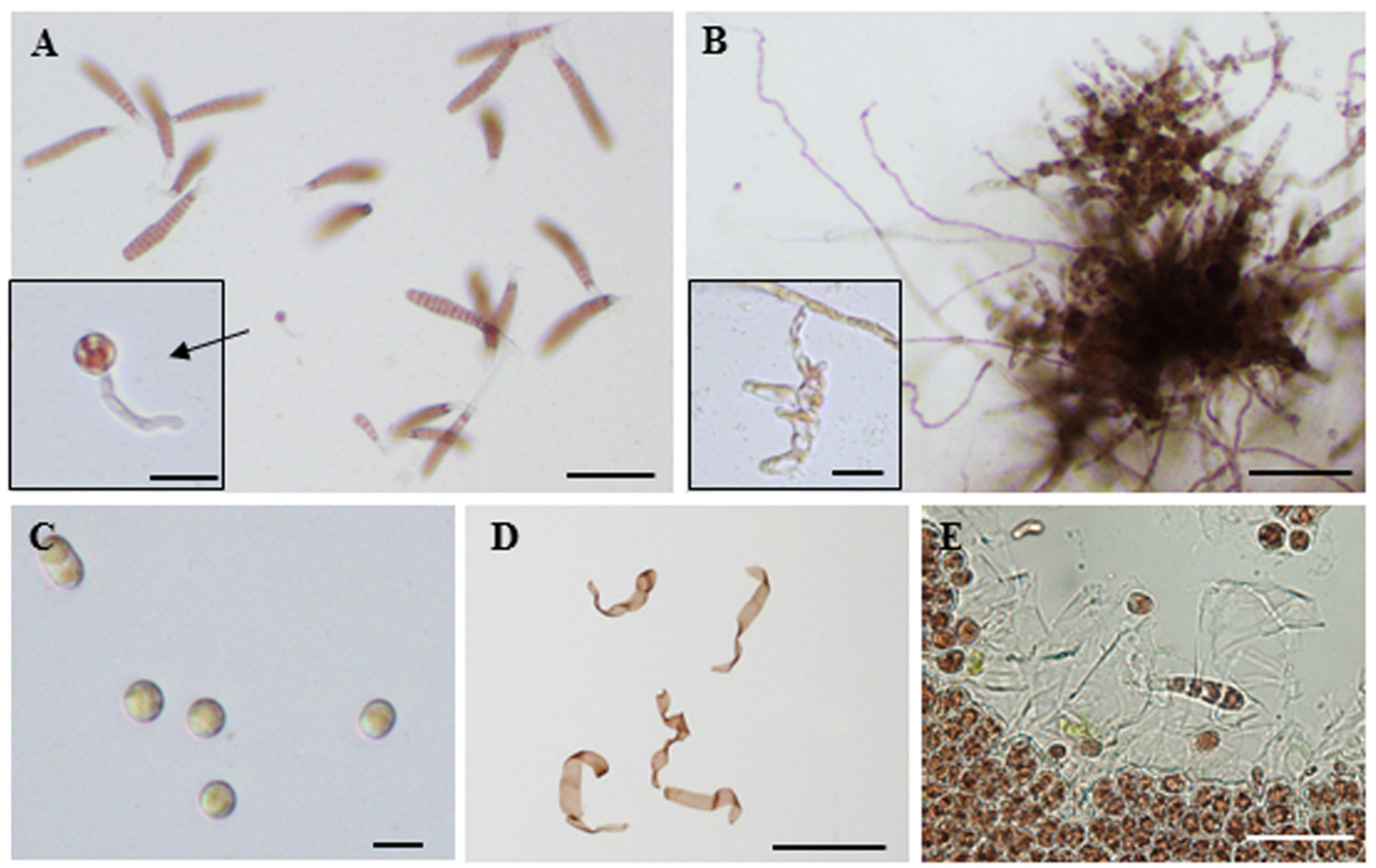

FIGURE 3 | Oxidative stress-triggered apogamy in Pyropia yezoensis. (A) Sporophyte and gametophytes released from spores from $\mathrm{H}_{2} \mathrm{O}_{2}$-treated gametophytic thallus. Most spores were monospores that developed into gametophytes. Enlarged view shows a sporophyte. (B) Filamentous sporophyte and conchosporangia (enlarged view) developed from a carpospore produced by apogamy. (C) Conchospores produced from conchosporangia. (D) Gametophytes developed from conchospores. (E) Discharge of monospores from gametophytes developed from apogamy-derived conchospores and normally growing monospore germlings. Scale bars = $100 \mu \mathrm{m}(\mathbf{A}, \mathbf{B}, \mathbf{E}), 20 \mu \mathrm{m}(\mathbf{C}$ and enlarged views in $\mathbf{A}$ and $\mathbf{B})$, and $1 \mathrm{~mm}$ (D).

cells, which might accelerate monospore production. In light of our results, wounding-dependent production of $\mathrm{H}_{2} \mathrm{O}_{2}$ might influence apogamy, because homogenization of allantoin-treated thallus was required for preparation of free cells (Saito et al., 2008). Indeed, sporophyte development by apogamy has been observed when protoplasts were prepared from gametophytes by artificial digestion of the cell wall (Waaland et al., 1990; Ar Gall et al., 1993). Our observation of $\mathrm{H}_{2} \mathrm{O}_{2}$-induced apogamy is consistent with these findings. Alternatively, the function of allantoin as a nitrogen source in algae (Anita et al., 1980; Prasad, 1983) suggests the involvement of nutritional conditions in apogamy in P. yezoensis. Therefore, it is necessary to examine whether ABA- and nitrogen-rich conditions induce apogamy in $P$. yezoensis and $P$. pseudolinearis to identify factors related to the initiation of apogamy in red seaweeds.

Elucidation of the relationship between the commitment to a developmental fate and the regulation of life-cycle progression is central to understanding the transitions between life-cycle generations. The $\mathrm{H}_{2} \mathrm{O}_{2}$-triggered apogamy identified in the present study suggests the presence of master regulators positively and negatively controlling ontogenies of life cycle generations in $P$. yezoensis as in terrestrial plants and the brown alga (Peters et al., 2008; Mosquna et al., 2009; Okano et al., 2009; Coelho et al., 2011b; Sakakibara et al., 2013; Horst et al., 2016). Since $\mathrm{H}_{2} \mathrm{O}_{2}$ treatment of released monospores did not produce any sporophytes (Takahashi and Mikami, unpublished), the fate of asexual spores appears to be fixed when they are released. Thus, we propose that precursors of thallus-derived unicellular spores have a competency to develop into both gametophyte and sporophyte, and that oxidative stress sometimes stimulates the selection of the conchospore developmental program before spore release. It is possible that distinct factors determining the early developmental process of monospores or carpospores before spore release might exist in P. yezoensis. In fact, we have already demonstrated that development of gametophytes starts with an asymmetrical cell division of the monospore to produce functionally distinct vegetative and rhizoid cells (Li et al., 2008) and also observed that filamentous conchocelis is produced by budding of the initial filament from a carpospore and subsequent elongation via symmetrical cell division and branching (unpublished). Therefore, reprogramming of developmental patterns might be closely related to switching of genetic programs regulating asymmetrical and symmetrical cell division. In addition, as in moss and brown seaweed (Peters et al., 2008; Mosquna et al., 2009; Okano et al., 2009; Coelho et al., 2011a,b; Sakakibara et al., 2013; Horst and Reski, 2016; Horst et al., 2016), it is possible that $P$. yezoensis has master regulators governing the expression of genes required for determination of gametophyte and sporophyte identities through asymmetrical and symmetrical cell division, respectively. However, these factors remain to be identified. 
Identification of master regulators and their target genes, both of which would be involved in determination of the developmental fate of unicellular spores from thallus, in $P$. yezoensis would help in understanding the relationships between expression of genetic programs regulating ontogenies of each generation and activation of the master regulators. In this respect, the artificial induction of apogamy reported in the present study has the potential to provide a breakthrough model system. In fact, apogamy in red seaweeds has been reported in Bangia fuscopurpurea and Pyropia haitanensis as spontaneously occurring (Notoya and Iijima, 2003; Yan et al., 2007), suggesting that apogamy is a natural strategy for generation switching in certain red seaweeds. By contrast, $P$. yezoensis apparently lacks this strategy, which is an advantage for investigating the molecular mechanisms regulating transitions of life-cycle generations in non-apomictic plants, like A. thaliana and Physcomitrella patens (Mosquna et al., 2009; Okano et al., 2009; Sakakibara et al., 2013; Horst et al., 2016).

\section{REFERENCES}

Anita, N. J., Berland, B. R., Bonin, D. J., and Maestrini, S. Y. (1980). Allantoin as nitrogen source for growth of marine benthic microalgae. Phycologia 19, 103-109. doi: 10.2216/i0031-8884-19-2-103.1

Ar Gall, E. (Le Gall, Y.), Chiang, Y.-M., and Kloareg, B. (1993). Isolation and regeneration of protoplasts from Porphyra dentata and Porphyra crispate. Eur. J. Phycol. 28, 277-283. doi: 10.1080/09670269300650391

Bai, C., Reilly, C. C., and Wood, B. W. (2006). Nickel deficiency disrupts metabolism of ureides, amino acids, and organic acid of young pecan foliage. Plant Physiol. 140, 433-443. doi: 10.1104/pp.105.072983

Bell, P. R. (1992). Apospory and apogamy: implication for understanding the plant life cycle. Int. J. Plant Sci. 153, 123-136. doi: 10.1086/297070

Blouin, N. A., Brodie, J. A., Grossman, A. C., Xu, P., and Brawley, S. H. (2011). Porphyra: a marine crop shaped by stress. Trends Plant Sci. 11, 29-37. doi: 10.1016/j.tplants.2010.10.004

Bowman, J. L., Sakakibara, K., Furumizu, C., and Dierschke, T. (2016). Evolution in the cycles of life. Annu. Rev. Genet. 50, 133-154. doi: 10.1146/annurev-genet120215-035227

Coelho, S. M., Godfroy, O., Arun, A., Le Corguillé, G., Peters, A. F., and Cock, J. M. (2011a). Genetic regulation of life cycle transitions in the brown alga Ectocarpus. Plant Signal. Behav. 6, 1858-1860. doi: 10.4161/psb.6.11.17737

Coelho, S. M., Godfroy, O., Arun, A., Le Corguillé, G., Peters, A. F., and Cock, J. M. (2011b). OUROBOROS is a master regulator of the gametophyte to sporophyte life cycle transition in the brown alga Ectocarpus. Proc. Natl. Acad. Sci. U.S.A. 108, 11518-11523. doi: 10.1073/pnas.1102274108

Foyer, C. H., and Shigeoka, S. (2011). Understanding oxidative stress and antioxidant functions to enhance photosynthesis. Plant Physiol. 155, 93-100. doi: 10.1104/pp.110.166181

Friedman, W. E. (2013). One genome, two ontogenies. Science 339, 1045-1046. doi: 10.1126/science.1234992

Herron, M. D., Rashidi, A., Shelton, D. E., and Driscoll, W. W. (2013). Cellular differentiation and individuality in the 'minor' multicellular taxa. Biol. Rev. Camb. Philos. Soc. 88, 844-861. doi: 10.1111/brv.12031

Horst, N. A., Katz, A., Pereman, I., Decker, E. L., Ohad, N., and Reski, R. (2016). A single homeobox gene triggers phase transition, embryogenesis and asexual reproduction. Nat. Plants 2:15209. doi: 10.1038/nplants.2015.209

Horst, N. A., and Reski, R. (2016). Alternation of generations - unravelling the underlying molecular mechanism of a 165 -year-old botanical observation. Plant Biol. 18, 549-551. doi: 10.1111/plb.12468

Li, L., Saga, N., and Mikami, K. (2008). Phosphatidylinositol 3-kinase activity and asymmetrical accumulation of F-actin are necessary for establishment of cell
The oxidative stress-dependent apogamy we have discovered in $P$. yezoensis provides novel insight into the developmental plasticity of the transitions between gametophytes and sporophytes in the seaweed life cycle and could be a good model for the study of life-cycle regulation.

\section{AUTHOR CONTRIBUTIONS}

MT performed the experiments and collected the data. MT and $\mathrm{KM}$ designed the research, analyzed the data, and wrote the manuscript.

\section{ACKNOWLEDGMENT}

We are grateful to the Marine Resources Research Center of Aichi Fisheries Research Institute for kindly providing P. yezoensis strain U51.

polarity in the early development of monospores from the marine red alga Porphyra yezoensis. J. Exp. Bot. 59, 3575-3586. doi: 10.1093/jxb/ern207

Mikami, K., Li, L., and Takahashi, M. (2012). "Monospore-based asexual life cycle in Porphyra yezoensis," in Porphyra yezoensis: Frontiers in Physiological and Molecular Biological Research, ed. K. Mikami (New York: Nova Science Publishers), 15-37.

Mikami, K., Mori, I. C., Matsuura, T., Ikeda, Y., Kojima, M., Sakakibara, H., et al. (2016). Comprehensive quantification and genome survey reveal the presence of novel phytohormone action modes in red seaweeds. J. Appl. Phycol. 28, 2539-2548. doi: 10.1007/s10811-015-0759-2

Mori, I. C., and Schroeder, J. I. (2004). Reactive oxygen species activation of plant $\mathrm{Ca}^{2+}$ channels. A signaling mechanism in polar growth, hormone transduction, stress signaling, and hypothetically mechanotransduction. Plant Physiol. 135, 702-708. doi: 10.1104/pp.104.042069

Mosquna, A., Katz, A., Decker, E. L., Rensing, S. A., Reski, R., and Ohad, N. (2009). Regulation of stem cell maintenance by the Polycomb protein FIE has been conserved during land plant evolution. Development 136, 2433-2444. doi: 10.1242/dev.035048

Notoya, M., and Iijima, N. (2003). Life history and sexuality of archeospore and apogamy of Bangia atropurpurea (Roth) Lyngbye (Bangiales, Rhodophyta) from Fukaura and Enoshima, Japan. Fish. Sci. 69, 799-805.

Okano, Y., Aono, N., Hiwatashi, Y., Murata, T., Nishiyama, T., Ishikawa, T., et al. (2009). A polycomb repressive complex 2 gene regulates apogamy and gives evolutionary insights into early land plant evolution. Proc. Natl. Acad. Sci. U.S.A. 106, 16321-16326. doi: 10.1073/pnas.0906997106

Peters, A. F., Scornet, D., Ratin, M., Charrier, B., Monnier, A., Merrien, Y., et al. (2008). Life-cycle- generation-specific developmental processes are modified in the immediate upright mutant of the brown alga Ectocarpus siliculosus. Development 135, 1503-1512. doi: 10.1242/dev.016303

Prasad, P. V. D. (1983). Hypoxanthine and allantoin as nitrogen sources for the growth of some freshwater green algae. New Phytol. 93, 575-580. doi: 10.1111/ j.1469-8137.1983.tb02708.x

Provasoli, L. (1968). "Media and prospects for the cultivation of marine algae," in Proceedings of the U.S.-Japan Conference: Cultures and Collections of Algae, eds A. Watanabe and A. Hattori (Hakone: Japanese Society of Plant Physiology), 63-75.

Rentel, M. C., and Knight, M. R. (2004). Oxidative stress-induced calcium signaling in Arabidopsis. Plant Physiol. 135, 1471-1479. doi: 10.1104/pp.104.042663

Sahoo, D., Tang, X., and Yarish, C. (2002). Porphyra - the economic seaweed as a new experimental system. Curr. Sci. 83, 1313-1316.

Saito, A., Mizuta, H., Yasui, H., and Saga, N. (2008). Artificial production of regenerable free cells in the gametophyte of Porphyra pseudolinearis (Bangiales, 
Rhodophyceae). Aquaculture 281, 138-144. doi: 10.1016/j.aquaculture.2008.06. 012

Sakakibara, K., Ando, S., Yip, H. K., Tamada, Y., Hiwatashi, Y., Murata, T., et al. (2013). KNOX2 genes regulate the haploid-to-diploid morphological transition in land plants. Science 339, 1067-1070. doi: 10.1126/science. 1230082

Schmidt, A., Schmid, M. W., and Grossniklaus, U. (2015). Plant germline formation: common concepts and developmental flexibility in sexual and asexual reproduction. Development 142, 229-241. doi: 10.1242/dev.102103

Shimizu, A., Morishima, K., Kobayashi, M., Kunimoto, M., and Nakayama, I. (2008). Identification of Porphyra yezoensis (Rhodophyta) meiosis by DNA quantification using confocal laser scanning microscopy. J. Appl. Phycol. 20, 83-88. doi: 10.1007/s10811-007-9184-5

Sutherland, J. E., Lindstrom, S. C., Nelson, W. A., Brodie, J., Lynch, M. D. J., Hwang, M. S., et al. (2011). A new look at an ancient order: generic revision of the Bangiales (Rhodophyta). J. Phycol. 47, 1131-1151. doi: 10.1111/j.15298817.2011.01052.x

Takagi, H., Ishiga, Y., Watanabe, S., Konishi, T., Egusa, M., Akiyoshi, N., et al. (2016). Allantoin, a stress-related purine metabolite, can activate jasmonate signaling in a MYC2-regulated and abscisic acid-dependent manner. J. Exp. Bot. 67, 2519-2532. doi: 10.1093/jxb/erw071

Takahashi, M., Saga, N., and Mikami, K. (2010). Photosynthesis-dependent extracellular $\mathrm{Ca}^{2+}$ influx triggers an asexual reproductive cycle in the marine red macroalga Porphyra yezoensis. Am. J. Plant Sci. 1, 1-11. doi: 10.4236/ajps. 2010.11001

Waaland, J. R., Dickson, L. G., and Watson, B. A. (1990). Protoplast isolation and regeneration in the marine red alga Porphyra nereocystis. Planta 181, 522-528. doi: 10.1007/BF00193005

Watanabe, S., Matsumoto, M., Hakomori, Y., Takagi, H., Shimada, H., and Sakamoto, A. (2014). The purine metabolite allantoin enhances abiotic stress tolerance through synergistic activation of abscisic acid metabolism. Plant Cell Environ. 37, 1022-1036. doi: 10.1111/pce.12218

Yan, X., Li, L., Chen, J., and Aruga, Y. (2007). Parthenogenesis and isolation of genetic pure strains in Porphyra haitanensis (Bangiales, Rhodophyta). Chin. High Technol. Lett. 17, 205-210.

Conflict of Interest Statement: The authors declare that the research was conducted in the absence of any commercial or financial relationships that could be construed as a potential conflict of interest.

Copyright (c) 2017 Takahashi and Mikami. This is an open-access article distributed under the terms of the Creative Commons Attribution License (CC BY). The use, distribution or reproduction in other forums is permitted, provided the original author(s) or licensor are credited and that the original publication in this journal is cited, in accordance with accepted academic practice. No use, distribution or reproduction is permitted which does not comply with these terms. 